\title{
PRÁCTICAS DE RESPONSABILIDAD SOCIAL Y GOBIERNO CORPORATIVO. UN ANÁLISIS PARA EL SECTOR BANCARIO DE SUGAMUXI'
}

\author{
Por: José Javier González Millán² ${ }^{2}$ Miryam Teresa Rodríguez Díaz³ , Jenny Mairena Herrera Rodríguez ${ }^{4}$
}

\section{RESUMEN}

Es claro hoy que la implementación de las prácticas de Responsabilidad Social Empresarial (RSE) y Gobierno Corporativo (G.C.) se está extendiendo progresivamente en las empresas como consecuencia de las diferentes presiones que reciben del entorno social así como del desarrollo de su propia conciencia empresarial. El presente artículo refiere los resultados de la investigación de campo hecha al sector bancario del valle de Sugamuxi, donde se aplicaron 170 encuestas a los Stakeholders asociados a las 10 entidades existentes en el Valle de Sugamuxi, la cual versará en primer lugar sobre las generalidades de la RSE y G.C., adicionalmente se caracterizaron los procesos de RSE, se identificaron las prácticas de G.C. En la parte metodológica, el tipo y método de estudio fue el descriptivo - explicativo; la técnica estadística utilizada propuesta es el análisis descriptivo (frecuencias), por último, la investigación da cuenta de las entidades bancarias poseen un nivel aceptable en mayor grado en terminos de la RSE, mas no en igual sentido en lo referente al G.C.

Palabras clave: responsabilidad social, gobierno, bancario, sector, grupos de interés. JEL: M14, M15, Q5.

1. Este artículo es producto de la investigación intitulada Estudio comparativo de las prácticas de responsabilidad social empresarial y gobierno corporativo del sector bancario del Valle de Sugamuxi en el departamento de Boyacá, de la Universidad Pedagógica y Tecnológica de Colombia perteneciente a la línea de investigación Gestión del Conocimiento, del grupo de investigación Management.

2. Magister en Administración Universidad Nacional de Colombia, Profesor Asistente Escuela de Administración de Empresas de la Facultad Sede Sogamoso de la Universidad Pedagógica y Tecnológica de Colombia, coordinador grupo de investigación Management, javier.gonzalezmillan@uptc.edu.co

3. Magister en Administración Universidad Nacional de Colombia, Especialista en Gestión del Talento Humano de la Universidad Pedagógica y Tecnológica de Colombia, Docente Auxiliar Escuela de Administración de Empresas UPTC, Investigadora grupo de investigación Management, miryamteresa. rodriguez@uptc.edu.co

4. Estudiante Administración de Empresas de la Facultad, sede Sogamoso, de la Universidad Pedagógica y Tecnológica de Colombia. Becaria de Investigación e Investigadora grupo de investigación Management, mairena0325@hotmail.com

Artículo recibido: 23 de enero de 2015.

Aprobación definitiva: 3 de junio de 2015. 


\title{
SOCIAL RESPONSIBILITY PRACTICES AND CORPORATE GOVERNANCE. ANALYSIS FOR BANKING SECTOR OF SUGAMUXI
}

By: José Javier González Millán, Miryam Teresa Rodríguez Díaz, Jenny Mairena Herrera Rodríguez

\begin{abstract}
It is clear today that the implementation of the practices of Corporate Social Responsibility (CSR) and Corporate Governance (CG) is spreading steadily in business due to the different pressures they receive from the social environment and the development of its own corporate awareness, Therefore, this article refers to the results of field research made the banking sector of Sugamuxi Valley, where 170 surveys were applied to the stakeholders associated with the 10 existing in the Valley of Sugamuxi entities, which will deal first place on the generalities of CSR and GC additionally CSR processes were characterized GC practices were identified in the methodological part, the type and method of study was descriptive - explanatory; given the statistical technique used is the descriptive analysis (frequency) finally realizes research banks have an acceptable level greater extent in terms of CSR, but not in the same direction in relation to $C G$.
\end{abstract}

Keywords: social responsibility, government, banking, sector, stakeholders. JEL: M14, M15, Q5. 


\title{
PRÁTICAS DE RESPONSABILIDADE SOCIAL E GOVERNANÇA CORPORATIVA. ANÁLISE DE SISTEMA BANCÁRIO SUGAMUXI
}

\author{
Por: José Javier González Millán, Miryam Teresa Rodríguez Díaz, Jenny Mairena Herrera Rodríguez
}

\section{RESUMO}

É hoje evidente que a implementação das práticas de Responsabilidade Social Empresarial (RSE) e Governança Corporativa (GC) está se espalhando de forma constante nos negócios devido às diferentes pressões que recebem do ambiente social e do desenvolvimento da sua própria consciência corporativa, Portanto, este artigo refere-se aos resultados de pesquisa de campo feita sector bancário Sugamuxi Valley, onde 170 inquéritos foram aplicadas às partes interessadas associadas com os 10 existentes no Vale de entidades Sugamuxi, que tratará primeiro colocar nas generalidades da RSC e GC, outros processos foram caracterizados CSR, práticas de GC foram identificados na parte metodológica, o tipo e método de estudo foi descritivo - explicativo; dada a técnica estatística utilizada é a análise descritiva (freqüência) finalmente percebe bancos de investigação têm um nível aceitável maior medida, em termos de responsabilidade social das empresas, mas não na mesma direção em relação ao GC

Palavras-chave: responsabilidade social, governo, bancos, indústria, grupos de interesse.

JEL: M14, M15, Q5. 
José Javier González Millán, Miryam Teresa Rodríguez Díaz, Jenny Mairena Herrera Rodríguez

\section{INTRODUCCIÓN}

Andrew Carnegie, cuyo pensamiento se guiaba por la piedad religiosa, consideraba que la riqueza no era para beneficio personal sino que debía estar encaminada como ayuda al prójimo, en tal sentido como jefe de Carnegie Stell Company, gastó en obras de caridad más de $\$ 400$ millones de dólares, lo que propició la quiebra de su empresa. Cuentan que a la muerte del señor Carnegie, ni sus propios herederos legítimos se vieron favorecidos por la herencia, pues la mayor parte de sus bienes los había dejado en caridad al prójimo. Andrew Carnegie tuvo la firme creencia que la riqueza debía ser utilizada para el bienestar del prójimo, pues estaba dicho en las Sagradas Escrituras que así podría alcanzar el Reino de los Cielos prometido por Jesús.

De la misma manera, Friedman (1970: 2) expresa que la responsabilidad social consiste en "Conducir los negocios de acuerdo con los deseos de ellos, que generalmente serán deseos de hacer tanto dinero como sea posible ateniéndose a las reglas básicas de la sociedad, tanto las incorporadas en la ley como las incorporadas en las costumbres éticas", así las cosas, el concepto de la Responsabilidad Social Empresarial (RSE) en el ámbito de los negocios, se ha convertido en una las ventajas competitivas del mundo moderno.

Por otra parte, el Gobierno Corporativo (G.C.) se ha venido acentuando como una de las mejores prácticas en relación con el medio donde se desarrollan las empresas modernas, por tal motivo es de acotar que la RSE se refiere a los Stakeholders (grupos de interés) y el G.C. tiene asiento en los órganos de alta dirección de la compañía, que para este caso se refiere a los socios o dueños de la misma, por estas razones, en el presente artículo pretende presentar las prácticas de estos dos temas en relación con las entidades pertenecientes al sector bancario Sogamoseño en el departamento de Boyacá. A partir de estas apreciaciones, se procura con el presente paper, mostrar los resultados de la investigación en las entidades bancarias del valle de Sugamuxi, haciendo una medición de las prácticas de Responsabilidad social y gobierno corporativo de las 10 empresas objeto de estudio, para obtener dicho fin, se aplicaron 170 encuestas estructuradas aleatorias (distribuidas entre los Stakeholders de cada entidad), para alcanzar este objetivo, se llevará en primer lugar, una revisión conceptual acerca del tema; en segundo lugar, la identificación de las prácticas de RSE existentes en las entidades financieras; en tercer lugar, se pretende hacer la identificación de las prácticas de G.C. de estas entidades; en lo concerniente a la parte metodológica Durango (2005), el tipo y método de estudio referirá al descriptivo - explicativo; la técnica estadística utilizada propuesta para el mapeo es el análisis descriptivo (frecuencias y tablas de contingencia), con el propósito de encontrar las variables importantes que permitan identificar las practicas existentes en esta compañías en torno a la Responsabilidad Social y el Gobierno Corporativo. 


\section{PLANTEAMIENTO DEL PROBLEMA DE INVESTIGACIÓN}

Con relación a este acápite, el objetivo primario intenta presentar de manera sucinta, una perspectiva de la problemática en el caso boyacense, de acuerdo a esto, es claro enfatizar que la Responsabilidad Social Empresarial se ha convertido al igual que el Gobierno Corporativo en dos temas de mucha resonancia en el ambiente empresarial, pero en la actualidad por ser la norma ISO 26000, al igual que otras tantas (Cuadro 1), son normas que no certifican, es decir solamente son guías no obligatorias, es decir que sus prácticas son definitivamente discrecionales y sujetas a la buena voluntad de los gerentes o de las juntas directivas en el mejor de los casos.

Cuadro 1. Guías de Responsabilidad Social y sus grados de cumplimiento

\begin{tabular}{|c|c|c|c|}
\hline $\begin{array}{l}\text { GUÍAS DE } \\
\text { CERTIFICACIÓN } \\
\text { SOCIAL }\end{array}$ & SA 8000 & SGE 21 & $\begin{array}{c}\text { OSHAS } 18000 \\
\text { (Occupational Health } \\
\text { and Safety Assessment } \\
\text { Series) }\end{array}$ \\
\hline ALCANCE & DERECHOS HUMANOS & $\begin{array}{l}\text { GESTIÓN ÉTICA } \\
\text { Y RESPONSABLE }\end{array}$ & $\begin{array}{l}\text { SEGURIDAD Y SALUD } \\
\text { EN EL TRABAJO }\end{array}$ \\
\hline $\begin{array}{c}\text { PERSPECTIVA } \\
\text { DE LA RSC EN LA } \\
\text { QUE PROFUNDIZA }\end{array}$ & $\begin{array}{c}\text { PERSPECTIVA SOCIAL } \\
\text { Y LABORAL } \\
\text { INTERNA Y EXTERNA }\end{array}$ & $\begin{array}{l}\text { TODAS LAS } \\
\text { PERSPECTIVAS } \\
\text { DE LA RSC }\end{array}$ & $\begin{array}{l}\text { PERSPECTIVA } \\
\text { LABORAL } \\
\text { INTERNA }\end{array}$ \\
\hline CERTIFICABLE & SI & SI & SI \\
\hline $\begin{array}{l}\text { PROPIETARIO } \\
\text { DEL ESQUEMA }\end{array}$ & $\begin{array}{l}\text { SOCIAL ACCOUNTABILITY } \\
\text { INTERNATIONAL (SAI) }\end{array}$ & FORÉTICA & BRITISH STANDARS \\
\hline DESCRIPCIÓN & $\begin{array}{l}\text { Desarrollo de están- } \\
\text { dares para certificar } \\
\text { el desempeño de las } \\
\text { Compañías en nueve } \\
\text { áreas: trabajo infantil, } \\
\text { trabajo forzoso, salud y } \\
\text { seguridad, libertad de } \\
\text { asociación, prácticas de } \\
\text { disciplina, discrimina- } \\
\text { ción, horas de trabajo, } \\
\text { compensación y admi- } \\
\text { nistración. }\end{array}$ & $\begin{array}{l}\text { Esta Norma, a modo } \\
\text { de documento marco, } \\
\text { desarrolla los criterios } \\
\text { que permiten estable- } \\
\text { cer, implantar y evaluar } \\
\text { en las organizaciones } \\
\text { el Sistema de Gestión } \\
\text { Ética y Socialmente } \\
\text { Responsable propuesto } \\
\text { por Foro para la Evalua- } \\
\text { ción de la Gestión Ética, } \\
\text { FORÉTICA. }\end{array}$ & $\begin{array}{l}\text { Son una serie de están- } \\
\text { dares voluntarios inter- } \\
\text { nacionales relacionados } \\
\text { con la gestión de segu } \\
\text { ridad y salud ocupacio- } \\
\text { nal, que buscan a través } \\
\text { de una gestión sistemá- } \\
\text { tica y estructurada ase- } \\
\text { gurar el mejoramiento } \\
\text { de la salud y seguridad } \\
\text { en el lugar de trabajo. }\end{array}$ \\
\hline
\end{tabular}


José Javier González Millán, Miryam Teresa Rodríguez Díaz, Jenny Mairena Herrera Rodríguez

\begin{tabular}{|c|c|c|}
\hline $\begin{array}{c}\text { GUÍAS DE } \\
\text { INFORMACIÓN } \\
\text { Y DE BALANCES }\end{array}$ & ISO 26000 & $\begin{array}{c}\text { GRI } \\
\text { GLOBAL REPORTING INITIATIVE }\end{array}$ \\
\hline ALCANCE & $\begin{array}{l}\text { GUÍA DE RESPONSABILIDAD } \\
\text { SOCIAL }\end{array}$ & $\begin{array}{l}\text { GUÍA PARA LA ELABORACIÓN DE } \\
\text { MEMORIAS DE SOSTENIBILIDAD }\end{array}$ \\
\hline $\begin{array}{l}\text { PERSPECTIVA DE } \\
\text { LA RSC EN LA QUE } \\
\text { PROFUNDIZA }\end{array}$ & $\begin{array}{c}\text { TODAS LAS PERSPECTIVAS } \\
\text { DE LA RSC }\end{array}$ & $\begin{array}{l}\text { SOCIAL, ECONÓMICO } \\
\text { Y AMBIENTAL }\end{array}$ \\
\hline CERTIFICABLE & $\begin{array}{l}\text { NO, ES SOLO UNA GUÍA } \\
\text { DE RECOMENDACIONES }\end{array}$ & $\begin{array}{l}\text { NO, ES SOLO UNA GUÍA } \\
\text { DE RECOMENDACIONES }\end{array}$ \\
\hline $\begin{array}{l}\text { PROPIETARIO DEL } \\
\text { ESQUEMA }\end{array}$ & ISO & $\begin{array}{c}\text { COALITION FOR } \\
\text { ENVIRONMENTALLY RESPONSABLE } \\
\text { ECONOMIES (CERES), Y } \\
\text { PROGRAMA DE LAS NACIONES } \\
\text { UNIDAS PARA EL MEDIO } \\
\text { AMBIENTE (PNUMA) }\end{array}$ \\
\hline DESCRIPCIÓN & $\begin{array}{l}\text { Proporciona orientación sobre } \\
\text { los principios que subyacen en } \\
\text { la responsabilidad social, el reco- } \\
\text { nocimiento de la responsabilidad } \\
\text { social y el involucramiento con las } \\
\text { partes interesadas, las materias } \\
\text { fundamentales y los asuntos que } \\
\text { constituyen la responsabilidad so- } \\
\text { cial y sobre las maneras de integrar } \\
\text { un comportamiento socialmente } \\
\text { responsable en la organización. }\end{array}$ & $\begin{array}{l}\text { Su misión es mejorar la calidad, } \\
\text { rigor y utilidad de los reportes de } \\
\text { sustentabilidad para que alcan- } \\
\text { cen un nivel equivalente al de los } \\
\text { reportes financieros. Se basa fun- } \\
\text { damentalmente en la implemen- } \\
\text { tación del triple balance (triple } \\
\text { bottom line), económico, social y } \\
\text { medioambiental. }\end{array}$ \\
\hline
\end{tabular}

Fuente: Elaboración propia, a partir de Det Norske Veritas (2010: 12- 13).

Con relación a estos temas, las empresas Boyacenses no son las más abanderadas, puesto que la visión de algunos ejecutivos se centra en la función económica que se orienta a generar compromisos de RSE y GC con los dueños de las entidades. De igual manera, es importante aclarar que la responsabilidad social incluye a muchos implicados como son los clientes externos, los cliente internos, la comunidad, el estado, los asociados, la sociedad y el medio ambiente, entre otros, es por esto que la presente investigación pretende entre otras cosas conocer cuáles son las prácticas de RSE Y GC presentes en este valle empresarial de Boyacá.

Un aspecto clave dentro de esta discusión es la falta de conciencia colectiva para entender mejor estos importantes temas, que deberían ser propios de la gerencia, pero que por la inversión económica que representan no son de la total aceptación de la alta dirección de las compañías. En este sentido, vale la pena acotar, que las entidades que sepan integrar adecuadamente la RSE en su estrategia y posteriormente en el nivel operativo, tendrán grandes posibilidades de conseguir ventajas 
competitivas en un mercado globalizado. Complementario a lo antes expuesto, la Gráfica 1, permite perfeccionar lo hasta aquí expuesto demostrando que existe un sinnúmero de necesidades a suplir en términos de la Responsabilidad Social Empresarial presentadas por Carroll (1991), las cuales no son cumplidas por algunas compañías y en otras de manera Filantrópica, a fin de obtener solo beneficios tributarios.

\section{Gráfica 1. Pirámide de Carroll}

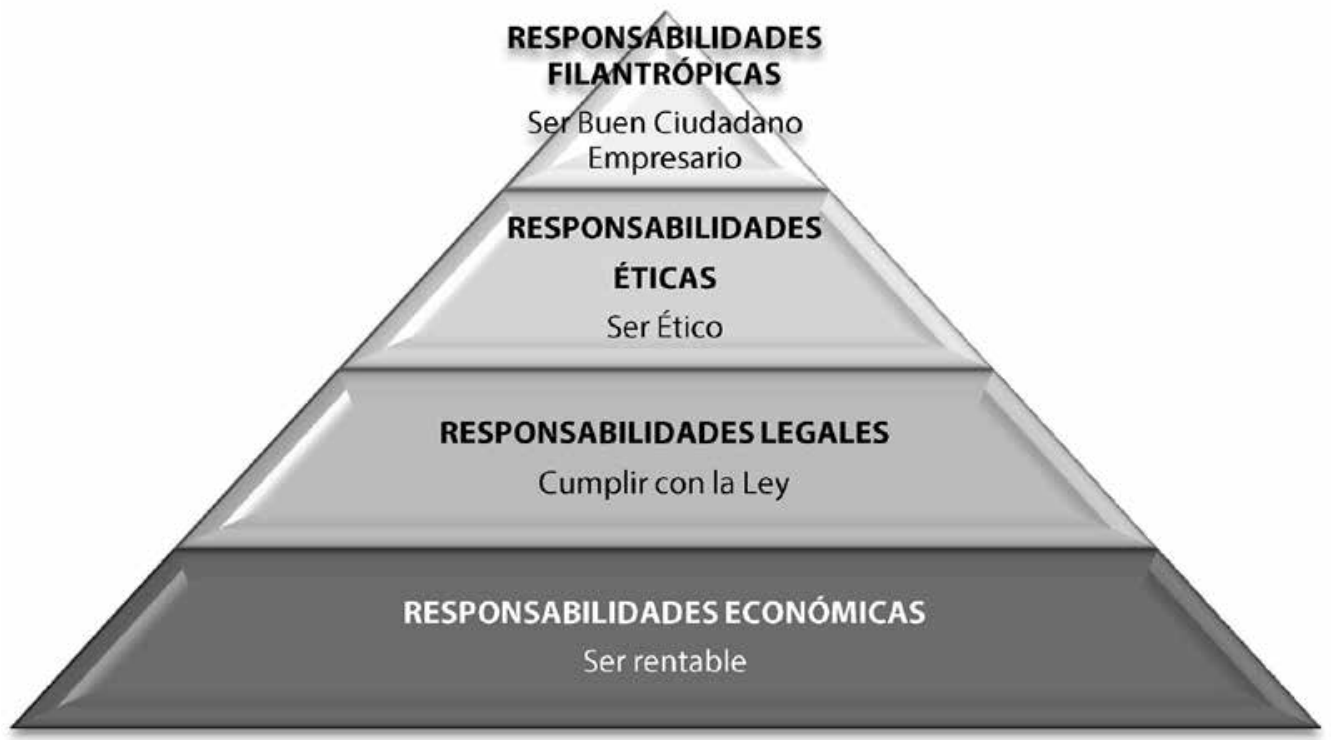

Fuente: Carroll, (1991: 5)

\section{MARCO TEÓRICO}

Con relación al objetivo de este capítulo, se pretende presentar un acercamiento conceptual de la temática abordada, de tal suerte, que cabe resaltar que en torno al objeto de estudio del artículo, existen infinidad de tratadistas que abordan la temática, llegando a concluir que no existe una concepción única, sino que depende de la corriente de turno.

\subsection{Principales Concepciones de la Responsabilidad Social Empresarial (RSE)}

En relación al tema, se encuentra un grupo de autores contemporáneos (Bigne, Chumpitaz, Andreu, y Swaen, 2005; Rodríguez, 2005; Mcwilliams, Siegel y Wright, 2006; Correa, 2007; Solís, 2008; Barroso y Francisco, 2008), al igual que otros tratadistas más modernos (Mellado, 2009; Álvarez y León, 2009; Crespo, 2010; Aguilar y Rauflet, 2010; Peña, 2012), por tal motivo, existen numerosas referencias teóricas 
respecto al tema, sin embargo se realiza una clasificación de las más relevantes y destacadas a lo largo del tiempo, las cuales se describen a continuación:

En primer lugar, es de citar los autores que han considerado la RSE como una carga económica, en tal sentido, aparece Friedman (2000: 5), quien consideraba que la única Responsabilidad Social de las empresas era "maximizar sus ganancias y que el compromiso social es un impedimento para la competitividad económica y el desempeño de las empresas”, así también, Drucker (2003: 8) expresa que ésta "consiste en la realización exitosa de su papel económico", por su parte, Carroll (1991: 39) la define en términos un poco más amplios, manifestando que ésta constituye "un concepto que comprende las expectativas económicas, legales, éticas y voluntarias o filantrópicas que la sociedad tiene de las organizaciones en un punto dado del tiempo".

Un segundo grupo, se refiere al tema desde varias perspectivas disciplinarias, incluyendo las ciencias sociales y la filosofía; es por esto que Davidson y Griffin (2000: 3) exponen que la RSE es "un grupo de obligaciones que una organización tiene para proteger y promover a la sociedad en la cual funciona", por su parte, Schermerhorn (2002: 3) sigue un enfoque similar considerándola como "la obligación de la organización para actuar en formas que sirven al interés propio y al interés de muchos stakeholders externos", no obstante lo expuesto, Boatright (2000: 3), analiza el tema teniendo en cuenta la actividad empresarial y afirma que ésta envuelve "la selección de metas corporativas y la evaluación de resultados no solamente por el criterio de las ganancias y bienestar organizacional, sino por los estándares éticos o juicios de deseo social”.

Un tercer grupo, lo configuran las organizaciones académicas, empresariales, y sin ánimo de lucro tanto a nivel Nacional como Mundial, así las cosas, se destaca, la Organización Internacional del Trabajo (OIT, 2007: 7), que declara la RSE como "un conjunto integral de políticas, prácticas y programas centrados en el respeto por la ética, las personas, las comunidades y el medio ambiente", de igual manera la Comisión Económica para América Latina y el Caribe (CEPAL, 2007:7) menciona que "la RSE hoy en día se refiere más bien a una forma de hacer negocios que toma en cuenta los efectos sociales, ambientales y económicos de la acción empresarial, integrando en ella el respeto por los valores éticos, las personas, las comunidades y el medio ambiente", así también, según el Banco Mundial (Banco Mundial, 2007: 7), reconoce la RSE como "el compromiso de las empresas para comportarse éticamente y para contribuir al desarrollo económico sustentable y la sociedad en general" . Por su parte, el Libro Verde (Libro verde, 2001: 8), la concibe como la "Integración voluntaria, por parte de las empresas, de las preocupaciones sociales y medioambientales en sus operaciones comerciales y en sus relaciones con sus interlocutores", consecuentemente con lo anterior, Forética de España (FORÉTICA, 2008: 9) , la explicita en la medida en que "trata de dotar a las organizaciones de herramientas que permitan planificar, monitorizar y evaluar el desarrollo de las relaciones de la empresa con todas las partes interesadas (stakeholders), conforme a unos valores compartidos por la organización"; de igual manera, para la orga- 
nización Comunicación de Responsabilidad Social de la Empresa en Argentina (COMUNICARSE, 2009: 9), esta es "una nueva forma de gestionar la práctica de los negocios que contempla una administración responsable de los impactos de las acciones de las empresas sobre su entorno económico, natural y social”.

En esta misma línea, el Centro Internacional para el Desarrollo Humano (CIDH, 2007: 11) de Costa Rica, la percibe como "una estrategia de negocios, la cual ha adquirido mucha importancia en el mundo de hoy. Las empresas, los gobiernos, las ONGs y la diversidad de actores que componen nuestras sociedades, constatan los beneficios de cambiar prácticas, comportamientos y nociones que han perjudicado la calidad de vida actual y amenazado la de generaciones futuras". Igualmente, para el caso mexicano, la entidad Aliarse (Aliarse, 2008: 12) concibe el tema como "el compromiso consciente y congruente que asume el empresario y la empresa de cumplir integralmente con la finalidad de la empresa tanto en lo interno, como en lo externo, considerando las expectativas de todos sus participantes en lo económico, social o humano y ambiental, demostrando el respeto por los valores éticos, las personas, las comunidades y la construcción del bien común con justicia social", continuando con esta visualización, en el caso de Uruguay, el Instituto Deres (DERES, 2010: 13) ha adoptado la siguiente definición: "La RSE es una visión de negocios que incorpora a la gestión de la empresa, el respeto por: los valores y principios éticos, las personas, la comunidad y el medio ambiente”, en esta misma línea, la Fundación Hondureña de Responsabilidad Social Empresarial (Fundarse, 2007: 12) la promueve como " un compromiso continuo de la empresa de contribuir al desarrollo económico sostenible, mejorando la calidad de vida de sus empleados y sus familias, así como de la comunidad local y de la sociedad en general". Finalmente en Colombia el (Centro Colombiano de Responsabilidad Empresarial (2012: 10) la define como la "Forma de gestionar una organización mediante la interacción y relación armónica con sus diferentes grupos de interés dando respuesta a sus expectativas financieras, sociales y ambientales de manera que se contribuya al desarrollo sostenible y a la creación de valor en todo el sistema”. De acuerdo a las anteriores percepciones se puede concluir que la RSE, obedece a un valioso compromiso social ético y moral que tienen las compañías de hoy para con los distintos grupos que tienen que ver con ella (clientes internos, clientes externos, proveedores, distribuidores, sociedad, estado, comunidades aledañas, sindicatos, propietarios y el medio ambiente), haciéndola sostenible y sustentable para las generaciones futuras.

\subsection{Enfoques de la RSE}

Como la Responsabilidad Social Empresarial es un tema de constante evolución, es importante y necesario interpretarlo desde diversos enfoques, con el fin de conocer los aportes y alcances que vienen teniendo desde hace varias décadas los promotores y defensores de la RSE, en donde se han involucrado todas y cada una de las relaciones que tiene el concepto con el medio económico, social y ambiental. Frente a este tema existen diferentes enfoques (Cuadro 2). 


\subsection{Gobierno Corporativo}

En lo relacionado a este ítem, diversos estudiosos (Lefort, 2003; Pineda y Torres, 2005; Longinos; García, Cortez y Rodríguez, 2009), se han referido a este tema como "un conjunto de prácticas, procesos y sistemas para dirigir y controlar una empresa. El Gobierno Corporativo regula las relaciones a nivel de accionistas, junta directiva y alta gerencia. También regula las relaciones de la empresa con los grupos de interés y fortalece la disposición ética de la compañía" (Córdoba y Vicentelli, 2009: 3).

\section{Cuadro 2. Grandes enfoques de la Responsabilidad Social Empresarial}

\begin{tabular}{|c|c|c|c|}
\hline TIPOS & CARACTERÍSTICAS & AUTORES & $\begin{array}{l}\text { RESPONSABILIDAD } \\
\text { ASUMIDA }\end{array}$ \\
\hline $\begin{array}{l}\text { Responsabilidad } \\
\text { social económica }\end{array}$ & $\begin{array}{l}\text { La responsabilidad de la } \\
\text { empresa es obtener bene- } \\
\text { ficios }\end{array}$ & $\begin{array}{l}\text { Friedman } \\
(1967)\end{array}$ & $\begin{array}{l}\text { - Responsabilidades } \\
\text { básicas. }\end{array}$ \\
\hline $\begin{array}{l}\text { Posiciones } \\
\text { intermedias }\end{array}$ & $\begin{array}{l}\text { Reconocen la existencia } \\
\text { de ciertos derechos de } \\
\text { algunos grupos sociales } \\
\text { que hay que satisfacer }\end{array}$ & $\begin{array}{l}\text { Watson } \\
(1972) \\
\text { Drucker } \\
(1970)\end{array}$ & $\begin{array}{l}\text { - Responsabilidades } \\
\text { básicas. } \\
\text { - Responsabilidades. } \\
\text { Organizacionales } \\
\text { (algunas). }\end{array}$ \\
\hline $\begin{array}{l}\text { Responsabilidad } \\
\text { social plena }\end{array}$ & $\begin{array}{l}\text { Dentro de los objetivos de } \\
\text { la empresa se incluyen los } \\
\text { sociales como una parte } \\
\text { importante }\end{array}$ & $\begin{array}{l}\text { Davis y } \\
\text { Blomstrom } \\
\text { (1966) } \\
\text { García Eche- } \\
\text { varría (1982) }\end{array}$ & $\begin{array}{l}\text { - Responsabilidades } \\
\text { básicas. } \\
\text { - Responsabilidades } \\
\text { organizacionales } \\
\text { - Responsabilidades } \\
\text { Societales }\end{array}$ \\
\hline
\end{tabular}

Fuente: Yepes, (2010: 17)

En referencia a este punto, Castro, Brown y Báez (2009), Ganga y Vera (2008), Fernández (2012), González (2012), coinciden globalmente en los beneficios que generan las buenas prácticas de Gobierno Corporativo, dentro de las cuales se destacan: Incrementar el valor de la sociedad, Facilitar su acceso al capital, Contribuir para su perennidad, Facilitar el acceso a un mayor volumen de financiamiento externo. Asi tambien, Córdoba y Vicentelli (2009), ponen de manifiesto, que el gobierno corporativo se basa en reducir o administrar de la mejor manera los conflictos de agenda que se presenten en la empresa con los diferentes grupos de interés. Principalmente reduce y mitiga la desalineación de intereses entre los Accionistas y administradores, Accionistas mayoritarios y minoritarios y la Empresa y sus grupos de interés. Asimismo el gobierno corporativo se basa en la comprensión de la estructura de dirección (Gráfica 2), el sistema de controles y los mecanismos de alineación de incentivos así: 


\section{Gráfica 2. Estructura del Gobierno Corporativo}

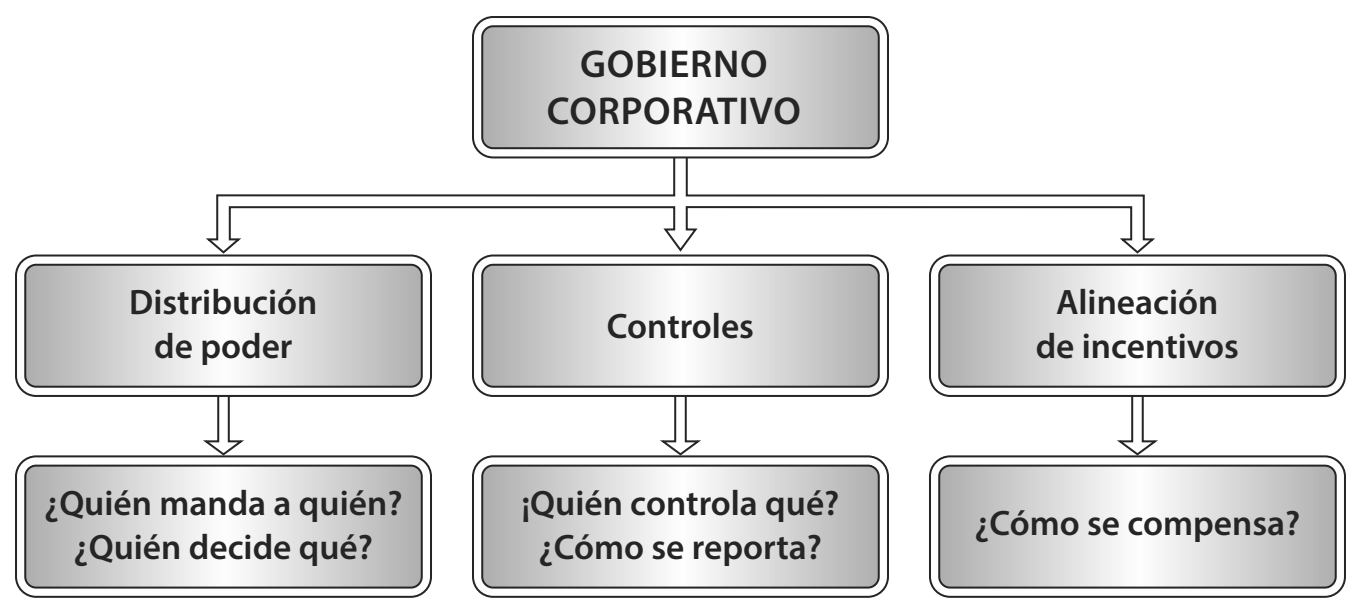

Fuente: Colombia Capital (2009: 7)

Por otra parte, Díaz (2010: 10), perceptua que para un adecuado proceso de Gobierno Corporativo es necesario llevar a cabo Buenas prácticas del consejo directivo, cumplir efectivamente con los procesos de control apropiados, de la misma forma poseer un Sistema fuerte de transparencia y revelación de la información, adicionado a un sistema de Protección de los derechos de los accionistas y un fuerte compromiso con las reformas de corporativo. De igual manera, el G.C. se rige bajo cuatro ejes, que refieren a la rendición de cuentas, la equidad, la transparencia y la responsabilidad corporativa, por tal motivo, todos estos son la base para que funcione correctamente, es claro entonces que estos ejes no funcionarían, sin soportarse en los tres principios básicos de gobierno corporativo que son la transparencia, revelación y responsabilidad (Gallego, García y Rodríguez, 2009; Lameira, Lee, Van Aduard, 2007).

Consecuentemente con lo anterior, se considera que un buen sistema de gobierno corporativo ejecuta bajo sus tres principios básicos las siguientes acciones (Díaz Danel, 2010): El trato igualitario y la protección de los intereses de todos los accionistas, El reconocimiento de la existencia de los terceros interesados en el buen desempeño, la estabilidad, y la permanencia en el tiempo de las sociedades, La emisión y revelación responsable de la información, así como la transparencia en la administración, El ejercicio de la responsabilidad fiduciaria del consejo de administración, La declaración de principios éticos y de responsabilidad social empresarial, El cumplimiento de las distintas regulaciones a que esté sujeta la sociedad y dar certidumbre y confianza a los inversionistas y terceros interesados sobre la conducción honesta y responsable de los negocios de las sociedades. 


\subsubsection{Objetivos de Gobierno Corporativo}

Maroto, Melle, Moreno y Rodríguez (2006), Pardo (2003), confluyen en establecer que existen objetivos del G.C., dentro de los cuales se destacan: Institucionalizar la toma de decisiones, Mejorar la gestión empresarial, Lograr ventajas competitivas, Mejorar el acceso a mercados financieros y Contribuir a la generación de valor.

\subsubsection{Beneficios del buen gobierno corporativo}

A continuación se mencionan algunos de los beneficios (Cuadro 3) que implica el buen gobierno corporativo (Córdoba y Vicentelli, 2009: 49):

\section{Cuadro 3. Comparativo e interacción entre Responsabilidad Social y Gobierno Corporativo}

\begin{tabular}{|c|c|}
\hline $\begin{array}{l}\text { GRUPO DE } \\
\text { INTERÉS }\end{array}$ & BENEFICIOS DEL GOBIERNO CORPORATIVO \\
\hline $\begin{array}{l}\text { Dueños de } \\
\text { la empresa } \\
\text { (accionistas) }\end{array}$ & $\begin{array}{l}\text { - Protege a los accionistas con un ejercicio ordenado de sus derechos. } \\
\text { - Garantiza la difusión de información oportuna y transparente de la situación } \\
\text { - Fortalece el proceso de toma de decisiones para que se adopten mejores } \\
\text { decisiones de negocios. } \\
\text { - Genera mecanismos idóneos para resolver conflictos entre los accionistas y } \\
\text { de los accionistas con los administradores o la propia empresa. } \\
\text { - En el caso de compañías cerradas y de familia, mitiga el riesgo de sucesión, } \\
\text { regula las relaciones de la familia-accionista como empleado proveedor o } \\
\text { cliente. }\end{array}$ \\
\hline Inversionistas & $\begin{array}{l}\text { - Los inversionistas se benefician del Gobierno Corporativo al contar con un } \\
\text { lenguaje basado en estándares internacionales que les permite entender las } \\
\text { características y el alcance de sus inversiones. } \\
\text { - Incluso si las compañías no contemplan fuentes de capital extranjero, adop- } \\
\text { tar buenas prácticas de Gobierno Corporativo se traduce en un aumento de } \\
\text { confianza por parte de los inversionistas locales, quienes se verán beneficia- } \\
\text { dos al contar con más y mejor información de la compañía. }\end{array}$ \\
\hline Acreedores & $\begin{array}{l}\text { - Los acreedores en su rol de monitoreo del deudor cuentan con reglas para } \\
\text { proteger la garantía de su acreencia, así como información oportuna y fia- } \\
\text { ble de la empresa/deudor. Esto facilita la comprensión del acreedor sobre la } \\
\text { situación real de la empresa, lo que se traduce en una reducción del riesgo } \\
\text { percibido y en mejores condiciones de endeudamiento para la compañía. }\end{array}$ \\
\hline $\begin{array}{l}\text { Otros Grupos } \\
\text { de interés }\end{array}$ & $\begin{array}{l}\text { - Los empleados, clientes, proveedores y demás grupos de interés de la com- } \\
\text { pañía son esenciales en el desempeño y continuidad de cada empresa. } \\
\text { - Por medio del Gobierno Corporativo se define una estrategia de administra- } \\
\text { ción trasparente y eficiente que promueve la articulación de las responsabi- } \\
\text { lidades de la compañía frente a cada grupo de interés. }\end{array}$ \\
\hline
\end{tabular}

Fuente: Elaboración propia, a partir de Córdoba y Vicentelli ( 2009: 16-17). 


\subsubsection{Comparación entre Responsabilidad Social y Gobierno Corporativo}

La Responsabilidad Social se hace cada vez más necesaria y cada vez debe estar más presente en el gobierno corporativo de las empresas; es por esto que en la Cuadro 4, se contrasta las características y ventajas de cada uno de los componentes señalados.

Cuadro 4. Comparativo e interacción entre Responsabilidad Social y Gobierno Corporativo

\begin{tabular}{|c|c|c|}
\hline & RESPONSABILIDAD SOCIAL & GOBIERNO CORPORATIVO \\
\hline Definición & $\begin{array}{l}\text { La Responsabilidad Social Empre- } \\
\text { sarial (RSE) es la contribución al } \\
\text { desarrollo humano sostenible, a } \\
\text { través del compromiso y la con- } \\
\text { fianza de la empresa hacia sus } \\
\text { empleados y las familias de éstos, } \\
\text { hacia la sociedad en general y ha- } \\
\text { cia la comunidad local, en pos de } \\
\text { mejorar el capital social y la cali- } \\
\text { dad de vida de toda la comunidad. }\end{array}$ & $\begin{array}{l}\text { El Gobierno Corporativo, es un } \\
\text { mecanismo de autorregulación de } \\
\text { normas, prácticas y procedimien- } \\
\text { tos, por medio del cual la sociedad } \\
\text { da normas para regular las relacio- } \\
\text { nes a largo plazo con sus grupos } \\
\text { de interés. }\end{array}$ \\
\hline Características & $\begin{array}{l}\text { Tiene como finalidad el encontrar } \\
\text { un equilibrio estable que satisfa- } \\
\text { ga las aspiraciones de las distin- } \\
\text { tas partes interesadas, tanto las } \\
\text { que intervienen como las que son } \\
\text { afectadas por la actuación de la } \\
\text { empresa. }\end{array}$ & $\begin{array}{l}\text { - Gestión responsable } \\
\text { - Buenas practicas } \\
\text { - Gobierno y política social } \\
\text { - Plan de negocios armonizado } \\
\text { con los intereses de la sociedad } \\
\text { - Relaciones con los públicos. }\end{array}$ \\
\hline $\begin{array}{l}\text { Ventajas del } \\
\text { concepto }\end{array}$ & $\begin{array}{l}\text { Aunque la RSE no es gratis, genera } \\
\text { ventajas en cuanto al mejoramien- } \\
\text { to de la productividad por parte } \\
\text { de los trabajadores, (...) reducción } \\
\text { de los costos de transacción para } \\
\text { con los accionistas, la calidad del } \\
\text { producto percibida por los con- } \\
\text { sumidores y una mayor demanda } \\
\text { por parte de los consumidores". } \\
\text { De la misma manera, la RSE mejo- } \\
\text { ra la imagen de las empresas, las } \\
\text { posiciona y las hace competitivas } \\
\text { diferenciándolas y garantizando } \\
\text { su supervivencia. }\end{array}$ & $\begin{array}{l}\text { En conjunto con una cultura basa- } \\
\text { da en la ética, un buen gobierno } \\
\text { corporativo es ideal para generar } \\
\text { un clima organizacional de con- } \\
\text { fianza y transparencia entre los } \\
\text { diferentes stakeholders, quienes } \\
\text { día a día demandan mayor infor- } \\
\text { mación y seguridad. } \\
\text { Lo anterior conducirá a mayor } \\
\text { competitividad y protección a la } \\
\text { inversión en la compañía }\end{array}$ \\
\hline
\end{tabular}

Fuente: Vergara y Vicaría (2009: 33).

Para concluir lo pertinente al gobierno corporativo, es importante aclarar el concepto que actualmente se maneja en las empresas y está ligado directamente con la responsabilidad social empresarial y amplia el término a la integración de los socios, accionistas, familias y directivos. 


\section{METODOLOGÍA}

De acuerdo a la temática suscitada en el presente documento corresponde a este capítulo esgrimir los aspectos metodológicos más importantes que soportan la investigación hecha en campo, discriminado así:

3.1 Tipo y método de investigación. Para alcanzar el objetivo propuesto en la investigación, fue necesario acudir a un estudio de carácter descriptivo-explicativo de acuerdo con Méndez (1998). El estudio permitirá realizar una interpretación de las variables, objeto de investigación, mediante una sistematización y análisis de la información, tarea que conducirá a una mejor descripción de las diferentes características propuestas en el estudio investigativo (Camacho, 2003: 36).

3.2 Fuente y técnica de recolección de información. Como fuentes primarias y de acuerdo con Tamayo (2002: 64), se tendrán en cuenta las que se aplicarán a gerentes o administradores y a trabajadores y stakeholders. Para la recolección de información, se utilizará como técnica la encuesta estructurada, la cual se estructuró con base en los instrumentos del Instituto Argentino de Responsabilidad Social (2005), encuesta de Fenalco-Autodiagnóstico Consultores Empresariales (2008). Para las fuentes secundarias se acudirá a estudios previos realizados en otras regiones de Colombia y del mundo. Además, se realizará la consulta de material documental.

3.3. Población, muestra, tipo de muestreo y tratamiento de la información. Se realizó una muestra de 170 encuestas distribuidas en 17 por entidad, para un total de 10 entidades y corporaciones bancarias de la ciudad de Sogamoso.

3.4. Ficha técnica propuesta. En el Cuadro 5, se presenta la ficha técnica que resume los elementos relevantes del diseño muestral:

\section{Cuadro 5: Ficha técnica tentativa del muestreo}

\begin{tabular}{|l|l|}
\hline Fecha de realización encuesta & Enero - Febrero de 2014 \\
\hline Institución & UPTC - Sogamoso \\
\hline Facultad & Sede Sogamoso \\
\hline Escuela & Administración de Empresas \\
\hline Departamento & Boyacá \\
\hline Zona de aplicación & VALLE DE SUGAMUXI \\
\hline Población & ENTIDADES Y CORPORACIONES BANCARIAS \\
\hline Tamaño de la población & 170 ENCUESTAS \\
\hline Procedimiento de recolección & Muestra \\
\hline Sistema de procesamiento & SPSS ${ }^{\text {TM }}$ (v. 20) \\
\hline Metodología: & Encuesta. Cuestionario Escrito (Fenalco, 2005) \\
\hline Unidad de análisis: & GERENTES, TRABAJADORES Y STAKEHOLDERS \\
\hline Realizador del estudio & Investigadores del proyecto. \\
\hline Prueba piloto & $\begin{array}{l}\text { Se aplicarón un total de } 10 \text { encuestas, distribuidas así: } 5 \text { en Bancos } \\
\text { y } 5 \text { en corporaciones. }\end{array}$ \\
\hline
\end{tabular}

Fuente: Autores. 


\section{RESULTADOS}

En relación a este capítulo, los objetivos se orientan a reiterar los de la investigación, los que se encuentran subdivididos en dos grandes grupos, distribuidas así, un primer fin se refiere a la RSE y un segundo objetivo versará sobre el tema de G.C.; en torno al primera, esta se discriminará en analizar aspectos como derechos laborales, medio ambiente, clientes y proveedores.

\subsection{EVALUACIÓN DE LA RESPONSABILIDAD SOCIAL EMPRESARIAL}

4.1.1 Derechos laborales. En esta acápite, se indagó si las entidades bancarias desarrollaban algún tipo de programas de entrenamiento para los nuevos empleados, en torno al tema el $86 \%$ afirmó que si reciben este tipo de adiestramiento, mientras que tan solo un $6 \%$ terminó expresando que No, adicionalmente a esto un $8 \%$ de los casos manifiestan no saber, esto porque son personal de contratación indirecta o por outsourcing, en este punto es claro que el sector bancario por la complejidad y responsabilidad del negocio requiere un proceso muy estricto de entrenamiento a su personal.

\section{Gráfica 3. Programas de entrenamiento al personal nuevo}

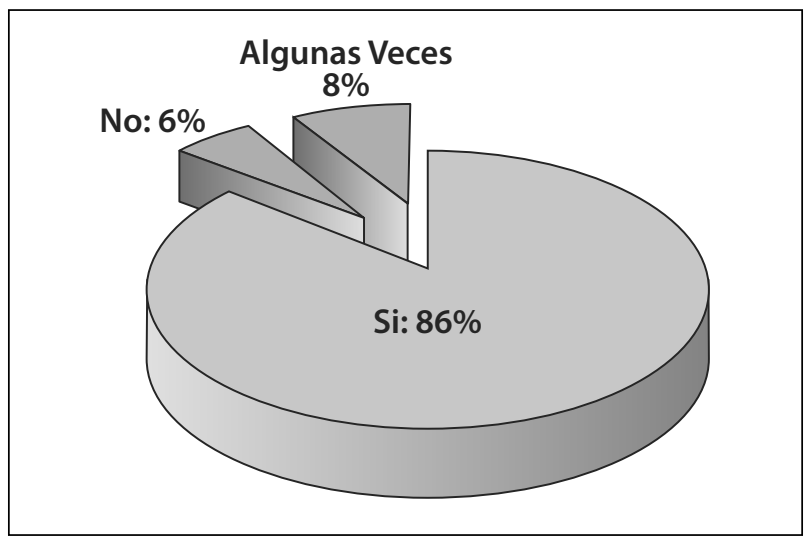

Fuente: Autores.

Un segundo punto abordado en esta temática, se refirió a si la entidad otorga a sus empleados beneficios adicionales a los exigidos por la Ley para el aumento de la calidad de vida de los mismos (Tabla 1), a lo cual los encuestados respondieron en $75,85 \%$ que si reciben este tipo de prestaciones y beneficios, dentro de las que más se destacan se encuentran primas extralegales, sobresueldos y apoyos para la formación universitaria, de la misma forma el 18,57\% manifestó no recibir ningún tipo de beneficio adicional establecido por la entidad, por último, el 8,58\% de los indagados expresó que solo algunas veces han recibido tal estímulo. 
Tabla 1. Beneficios adicionales a los de Ley para los empleados

\begin{tabular}{|c|c|}
\hline Respuesta & Valor Porcentual \\
\hline $\mathrm{Si}$ & 72,85 \\
\hline No & 18,57 \\
\hline Algunas Veces & 8,58 \\
\hline
\end{tabular}

Fuente: Autores.

Un tercer punto indagado en esta perspectiva, tuvo que ver con si la entidad tiene políticas establecidas en contra del trabajo infantil (Tabla 2), ante esta pregunta, la gran mayoría $(75,71 \%)$ contestó que indiscutiblemente si existen formalmente dichas políticas, mas sin embargo, el restante porcentaje $(24,21 \%)$ consideró que no existen o simplemente no las conocen, es claro en este punto que muy pocas veces se encuentran menores de edad trabajando en las entidades bancarias, salvo los aprendices del SENA o los practicantes de institutos de formación afín a labor financiera.

Tabla 2. Existencia de políticas contra el trabajo infantil

\begin{tabular}{|c|c|}
\hline Respuesta & Valor Porcentual \\
\hline $\mathrm{Si}$ & 75,71 \\
\hline No & 24,21 \\
\hline
\end{tabular}

Fuente: Autores.

El cuarto ítem hizo referencia a si en la empresa se garantizan las medidas de seguridad y prevención del riesgo (Tabla 3), allí las cifras fueron contundentes con un valor del 95,71\% manifiestan que existe garantía para ello, pues tan solo un $1,44 \%$ responde que no existen las precitadas medidas, mientras que el 2,85\% restante confiesa que estas se presentan algunas veces.

Tabla 3. Existencia de las medidas de seguridad y prevención del riesgo

\begin{tabular}{|c|c|}
\hline Respuesta & No. \\
\hline $\mathrm{Si}$ & 95,71 \\
\hline No & 1,44 \\
\hline Algunas Veces & 2,85 \\
\hline
\end{tabular}

Fuente: Autores.

Un quinto elemento evaluado, fue si se consulta a los funcionarios periódicamente sobre las estrategias para el mejoramiento de la empresa (Gráfica 4), ante lo cual los encuestados respondieron que si son consultados (66\%) para tomar esta decisiones, a su vez el 18\% expresa que no son consultados, por su parte un 16\% expresó que algunas veces son tenidos en cuenta para este fin. 


\section{Gráfica 4. Consulta a funcionarios sobre estrategias de mejoramiento empresarial}

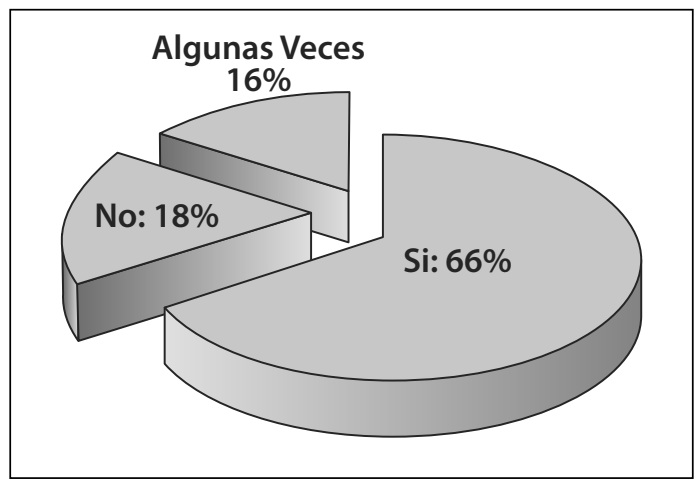

Fuente: Autores.

Por otra parte una valiosa inquietud sugerida fue si la institución promueve el equilibrio entre la vida laboral y la vida familiar (Gráfica 5), lo que arrojó como resultado que un $74,28 \%$ encuentran un equilibrio favorable entre estos dos roles propios del trabajador, en su orden el $17,14 \%$ no encuentra que exista esta promoción al interior de la entidades, mientras que una menor proporción $(8,58 \%)$ han sentido esta promoción en algunas ocasiones.

\section{Gráfica 5. Promoción del equilibrio entre la vida laboral y familiar}

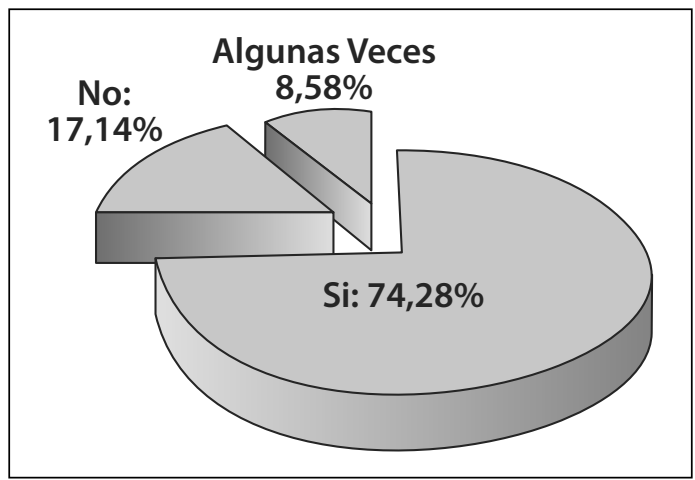

Fuente: Autores.

Un aspecto adicional refirió a si la organización desarrolla programas de capacitación y gestión de habilidades para sus empleados, ante lo cual el 67,14\% afirmó que si se desarrollan estos programas (Tabla 4), mientras que el 18,57\% expresa no poseer estos tipos de planes, de la misma manera el 14,29\% considera que esto se presenta en algunas ocasiones. 
Tabla 4. Desarrollo de programas de capacitación y gestión de habilidades para empleados

\begin{tabular}{|l|c|}
\hline \multicolumn{1}{|c|}{ Respuesta } & Valor Porcentual \\
\hline Si & 67,14 \\
\hline No & 18,57 \\
\hline Algunas Veces & 14,29 \\
\hline
\end{tabular}

Fuente: Autores.

\subsubsection{Derechos humanos}

Una segunda variable evaluada, hizo alusión a los derechos humanos, dentro de los cuales se indagó en primer lugar si la entidad tiene establecidas políticas de discriminación por sexo, religión o raza (grafica 6), allí el 66\% puso de manifiesto que no existen dichas políticas, mas sin embargo un 34\% de los encuestados considera que si hay procesos de discriminación en distintas modalidades.

Con relación a si se establece políticas para la vinculación laboral de personas en situación de discapacidad, los stakeholders vinculados respondieron que la gran mayoría (67\%) no conocen de este tipo de actividades o de personas que con estas discapacidades laboren en las entidades, pues tan solo un $27 \%$ expreso que en sus entidades si hay mecanismos de vinculación de estas personas (Gráfica 7).

\section{Grafica 6. Promoción del equilibrio entre la vida laboral y familiar}

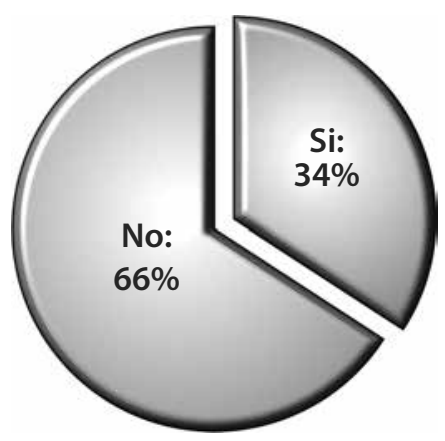

Fuente: Autores.

\section{Grafica 7. Vinculación de discapacitados a la entidad}

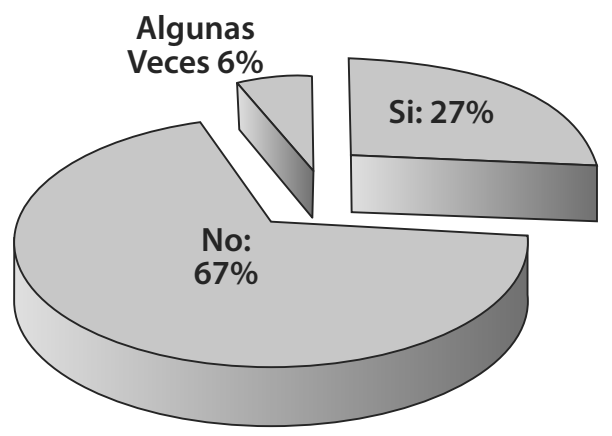

Fuente: Autores.

4.1.3 Clientes. Por otro lado se encontró también que al averiguar si en la empresa se realizan mediciones constantes de satisfacción de clientes, quedó claro que el $77 \%$ de los interrogados afirmó que se llevan a cabo estas prácticas y tan solo un 16\% confirma que no se hace ningún tipo de encuestas o mecanismos de satisfacción al cliente (Gráfica 8). 


\section{Grafica 8. \\ Mediciones de satisfacción al cliente}

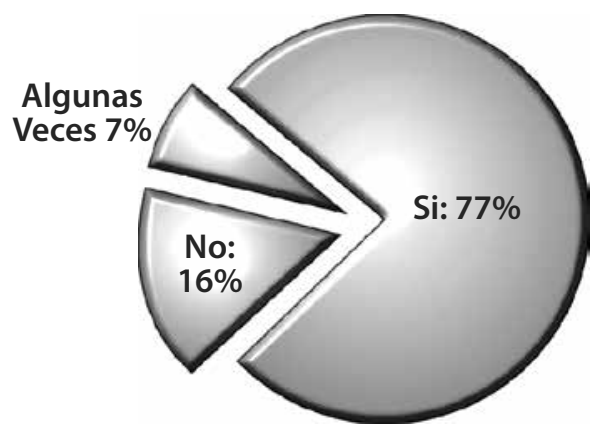

Fuente: Autores.

\section{Grafica 9. Establecimiento de políticas de publicidad no engañosa}

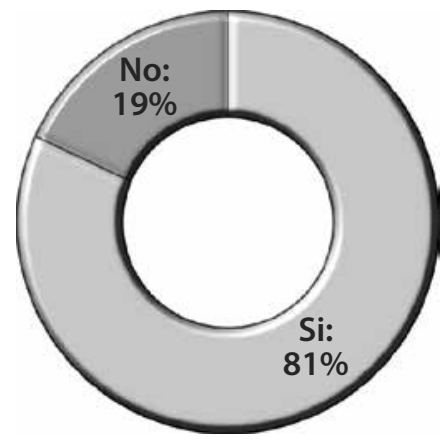

Fuente: Autores.

También se averiguó si la organización establece políticas de publicidad no engañosa, en este caso el $81 \%$ afirmó que no existen tales prácticas, mientras que tan solo el 19\% dijo que si hace uso o presume que se realizan tales políticas( Gráfica 9).

4.1.4 Medio Ambiente. En lo referente a la parte ambiental, se preguntó a los implicados si la entidad lleva a cabo acciones para el ahorro de energía, agua y recursos naturales, en la cual el $87 \%$ de los investigados afirmaron que la empresa lleva a cabo acciones muy sencillas, pero efectivas para este fin, tan solo un 9\% expresó que no (Gráfica 10).

\section{Gráfica 10. La empresa lleva acciones para ahorro de energía, agua y recursos naturales}

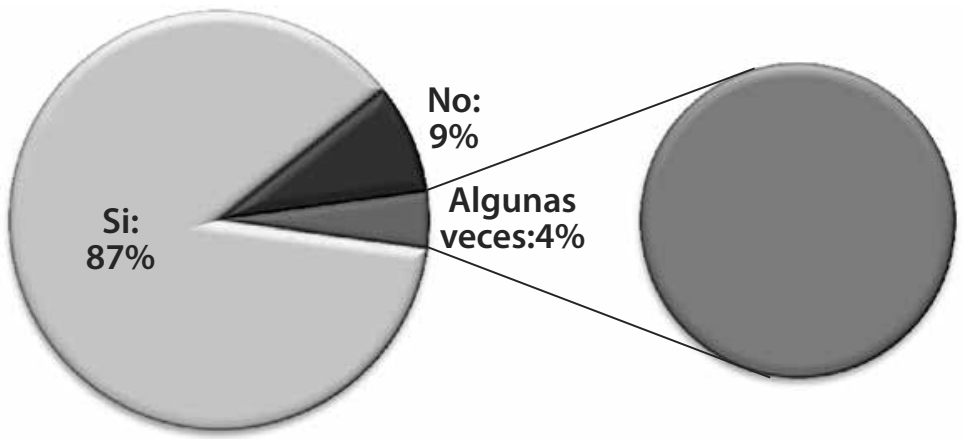

Fuente: Autores.

Otro elemento de escudriñamiento, lo constituye el tema de si la empresa cumple con las normas ambientales, en la cual el 91\% considero que la entidad efectivamente cumple con las normas e incluso se encuentran certificadas con la norma ambiental, de la misma manera, un $6 \%$ expreso que no hay cumplimiento en las normas ambientales (Gráfica 11). 


\section{Gráfica 11. La empresa cumple con las normas ambientales}

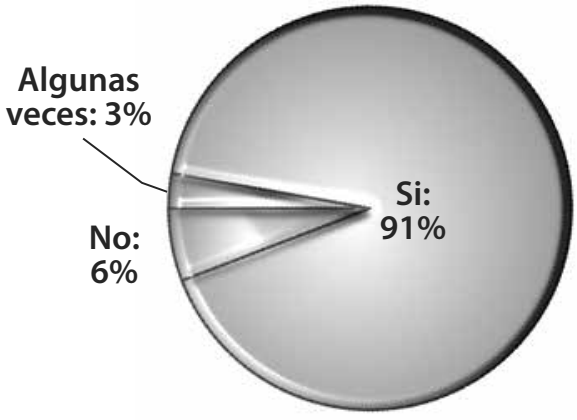

Fuente: Autores.

\section{Gráfica 12. La empresa implementa programa para el manejo de residuos y reciclaje}

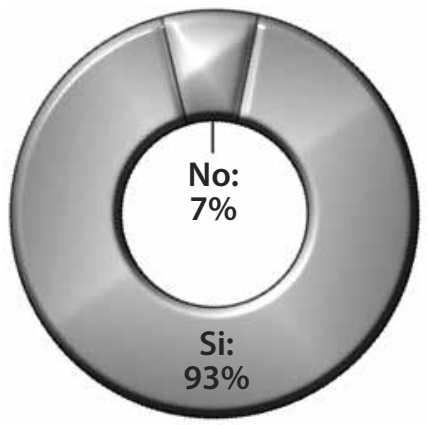

Fuente: Autores.

Otra variable hallada en el tema ambiental, correspondió a la Implementación de programas para el manejo de residuos y reciclaje, allí concluyó que el 93\% de los encuestados afirmó que si existe un programa de manejo de residuos y tan solo un 7\% demuestra que la empresa no posee dicho plan (Gráfica 12).

En este punto, se averiguó sobre si la organización capacita regularmente a sus empleados y personal sobre el tema ambiental, en el cual el 64,28\% respondió afirmativamente, pues el 24,28\% consideró que no se presenta ninguna acción de capacitación en torno al tema (Gráfica 13).

\section{Gráfica 13. La empresa implementa programa para el manejo de residuos y reciclaje.}

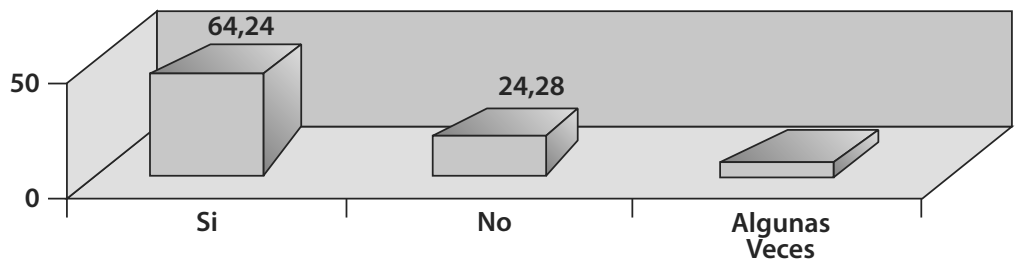

Fuente: Autores.

Otro valioso ítem tenido en cuenta en la parte ambiental lo constituyó el interrogante de si controla la contaminación causada por la operación de la empresa, donde el $86 \%$ de los indagados afirmó que Si, pues tan solo el 13\% considera que la empresa deja al garete los controles ambientales (Gráfica 14).

Para concluir este aspecto ambiental, se inquirió sobre las inversiones ambientales que realiza la entidad, se notó claramente que solo un 34\% de los encuestados conoce acerca de alguna acción ambiental, en tanto que un 57\% afirma que definitivamente no hay inversión en el tema ambiental, aspecto preocupante para entidades de este nivel, que aunque no generan gran afectación al medio, si poseen los recursos necesarios para llegar a aportar a este importante eje de la RSE (Gráfica 15). 
Gráfica 14. La empresa hace controles contra la contaminación causada por la empresa

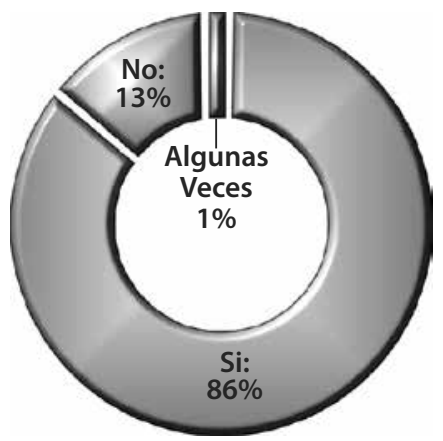

Fuente: Autores.

\section{Gráfica 15. La empresa cuenta con} Inversiones ambientales

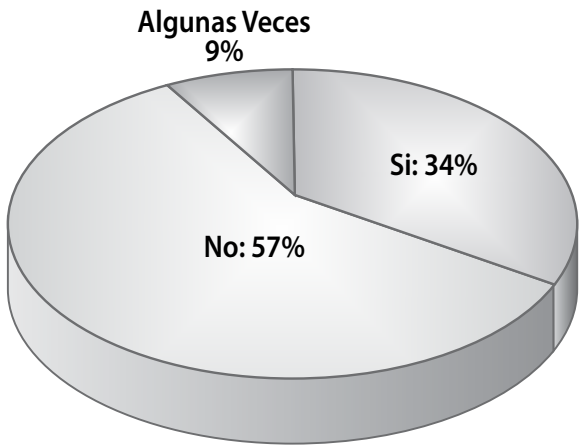

Fuente: Autores.

\subsection{DIRECCIÓN Y GOBIERNO CORPORATIVO}

El primer elemento evaluado en esta parte correspondió a la identificar si la empresa cuenta con valores institucionales escritos en un documento o medio de difusión, en el que se encontró que el 79\% de los investigados confirmó que estos valores se encuentran normalizados y documentados al interior de la institución, es importante aclarar que un 21\% consideró que estos no se encuentran claramente, tal vez por desconocimiento de la estructura empresarial, propia de su corto tiempo en las organizaciones objeto de estudio (Gráfica 16).

Gráfica 16. La empresa cuenta con valores institucionales documentados.

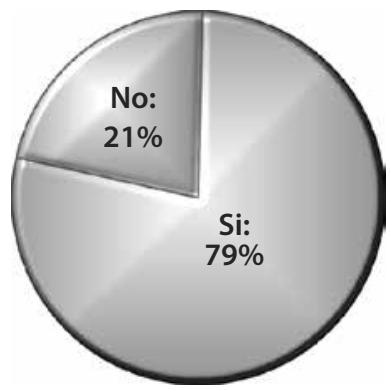

Fuente: Autores.

Un importante factor evaluado en este aspecto, permitió averiguar si en la organización se prohíbe explícitamente prácticas corruptas, quedando claro que el 97,14\% de los encuestados dice que estas nefastas actividades son prohibidas a nivel institucional, como complemento a esto un porcentaje del 2,86\% consideró que la entidad no hace ninguna prohibición explícita de estas prácticas (Gráfica 17). 


\section{Gráfica 17. Prohibición de las políticas corruptas en la empresa}

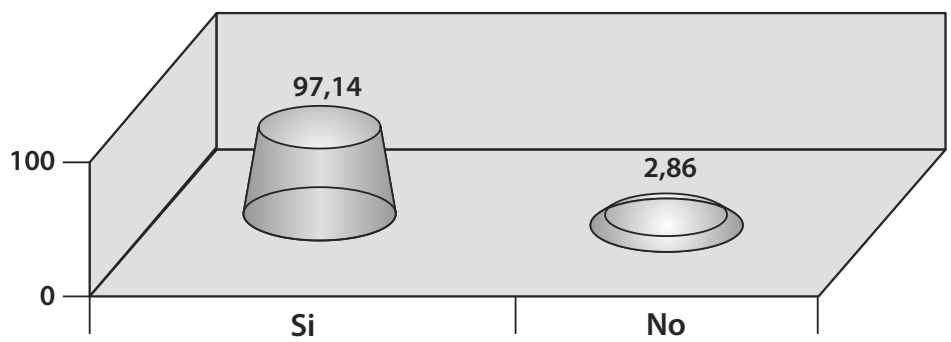

Fuente: Autores.

Otro aspecto evaluado en la temática del Gobierno Corporativo, se refirió a si la entidad bancaria promueve el manejo adecuado de conflictos, aspecto en el cual los investigados respondieron certeramente que si (96\%), mientras que tan solo un 3\% consideran que No, mientras que el ítem de algunas veces alcanzó un valor porcentual de 1\% (Gráfica 18).

Un aspecto muy relevante que se tuvo en cuenta en este punto, lo constituyó, el aspecto social, ante el cual los encuestados respondieron en un $96 \%$ que si se llevan a cabo dichas prácticas por parte del gobierno empresarial de la entidad, de otro lado tan solo un 4\% contesta que definitivamente no se hacen estas actividades en la compañía (Gráfica 19).

\section{Gráfica 18. La entidad promueve el manejo} adecuado a la solución de conflictos

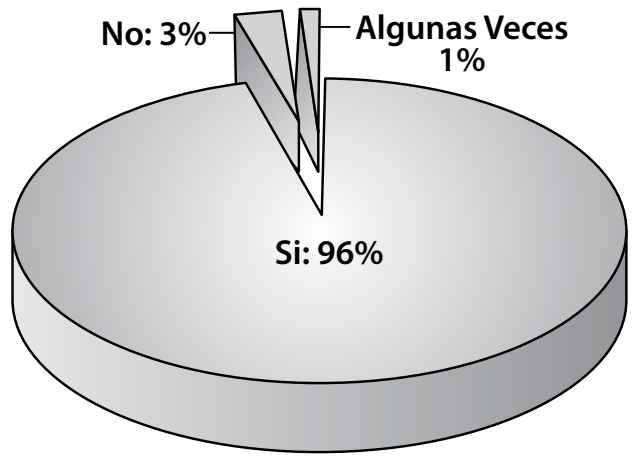

Fuente: Autores.

\section{Gráfica 19. Prácticas sociales por parte del gobierno de la empresa}

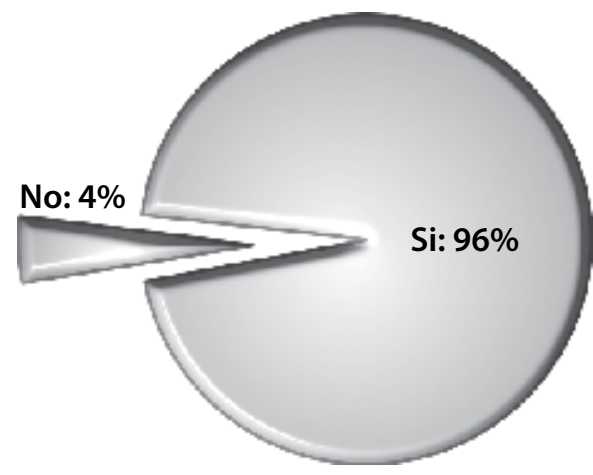

Fuente: Autores.

Por último se investigó sobre si la empresa maneja bajo criterios éticos las relaciones externas e internas, ante lo cual la inmensa mayoría (89\%) contestó que si se llevan a cabo estos comportamientos, por su parte un 11\% explicó que no conocen que se lleven a cabo estas prácticas (Gráfica 20). 


\section{Gráfica 20. Utilización de criterios éticos en las relaciones externas e internas.}

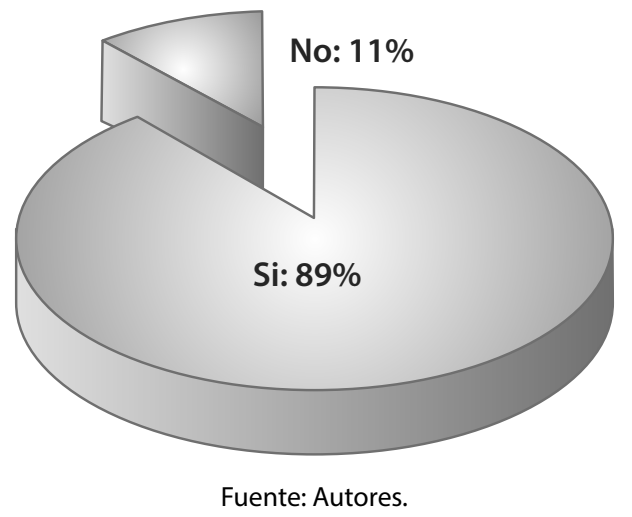

\section{CONCLUSIONES}

En torno al trabajo investigativo se puede concluir que el sector bancario Sogamoseño se encuentra comprometido en nivel aceptable, con un grado alto de aplicación de las políticas de Responsabilidad Social Empresarial, en tanto que en Gobierno corporativo el compromiso es menor, pues en términos generales las empresas cumple con los mínimos del G.C.

Con relación a las prácticas de medio ambiente, la gran mayoría de los interrogantes tiende a cumplir con los requisitos mínimos como son campañas, y generación de cultura, más no inversión económica en obras de medio ambiente. De la misma manera queda claro que estas organizaciones tienen establecidas prácticas de ahorro de energía, de agua y de recursos naturales al interior de éstas.

Con relación a los clientes internos el estudio arrojó que se presentan programas de entrenamiento y de capacitación acordes con la razón de ser, estas son aplicadas no solo con los nuevos empleados, en tal sentido, las organizaciones del sector ofrecen a sus empleados prestaciones y beneficios extralegales a los oficialmente establecidos por la ley Colombiana, por último se encuentra que las entidades tienen establecidos las medidas de seguridad y salud ocupacional para los funcionarios.

En la parte de derechos humanos no se presenta el trabajo infantil, tan solo con los casos de practicantes de instituciones tecnológicas o técnicas de formación, inquieta en este aspecto que una tercera parte de los encuestados considera que existen prácticas de discriminación ya sea por sexo, por edad o por otro tipo de condición.

En la perspectiva de los clientes, se identificó que las 2/3 partes de los clientes externos considera que si existe al interior de las entidades prácticas de medición de la calidad y de servicio al cliente, ya sean estas por medios virtuales o por mecanismos telefónicos o por encuestas. 
En torno al gobierno corporativo es claro que no se presentan políticas corruptas, ni tampoco inexistencia de valores que propendan por la posición ética y moral correcta, así también se concluyó que este sector no es permisivo con prácticas de publicidad engañosa para con la competencia, de igual manera se respeta la competencia sin competencia desleal. En este mismo punto quedó claro que al interior de la organización existe un sistema de solución de conflictos e incluso comité u organismos de conciliación

Para concluir este punto del G.C., la entidad cumple en gran medida con la normativización de los valores de manera formal para todos los miembros de la organización.

\section{REFERENCIAS}

1. ALIARSE. (2008). Análisis del concepto de Responsabilidad Social Empresarial. International Journal of Good Conscience, 12. [en línea] Disponible http://www.cce.org.mx/NR/exeres/F638C6C1-0D8444AD-AA81-57432B8D2DDF,frameless.htm?NRMODE=Published (Consultado jul. 9-14)

2. ÁLVAREZV., AQUILES, Fátima (2009). Debilidades de la globalización y el papel de la responsabilidad social empresarial. En: Economía. Núm. 27 Enero-Junio, pp. 87-119 [en línea] Disponible en:<http:// www.redalyc.org/articulo.oa?id=195614958005 $>$ (Consultado sep. 22-14)

3. BANCO MUNDIAL (27 de octubre de 2007). Analisis del concepto de Responsabilidad Social Empresarial. Daena: International Journal of Good Conscience, 7.

4. BARROSO, Tanoira; FRANCISCO, Gerardo (2008). La responsabilidad social empresarial. Un estudio en cuarenta empresas de la ciudad de Mérida, YucatánContaduría y Administración. Núm. (226). pp. 73-91. [en línea] Disponible en:<http://www.redalyc.org/articulo.oa?id=39522605> (Consultado jul. 9-14)

5. BIGNÉ, Enrique; CHUMPITAZ, Ruben; ANDREU, Luisa; SWAEN, Valerie (2005). Percepción de la responsabilidad social corporativa: un análisis cross-cultural. Universia Business Review. Vol. 5. pp. 14-27. [en línea] Disponible en:http://www.redalyc.org/articulo.oa?id=43300503 (Consultado sep. 22-14).

6. CAMACHO, Briceida (2003). Metodología de la Investigación científica, un camino fácil de recorrer para todos. Tunja, Colombia: Universidad Pedagógica y Tecnológica de Colombia. 
7. CARROLL, Archie (1991). The pyramid of corporate social responsibility: toward the moral management of organizational stakeholders. Business Horizons, Vol 34. Núm, 4. pp. 39-48 [en línea] Disponible en:<http://www.sciencedirect.com/science/article/pii/000768139190005G (Consultado jul. 9-14)

8. CASTRO, Santiago; BROWN, Cynthia; BÁEZ, Aníbal (2009). Prácticas de gobierno corporativo en América Latina Academia. Revista Latinoamericana de Administración. Vol. 43. pp 26-40 [en línea]. Disponible en:<http://www.redalyc.org/articulo.oa?id=71612112003> ISSN 1012-8255 (Consultado sep. 22-14)

9. CENTRO COLOMBIANO DE RESPONSABILIDAD EMPRESARIAL, C. (2012). Indicadores de Responsabilidad Social. Construyendo Confianza, 1.

10. CEPAL (2007). Análisis del concepto de Responsabilidad Social Empresarial. International Journal of Good Conscience, 7.

11. CIDH (2007). Análisis del concepto de Responsabilidad Social Empresarial. International Journal of Good Conscience, 11 [en línea]. Disponible en: http://www.cidh.ac.cr/corporate.html (Consultado sep. 22-14).

12. COMUNICARSE (2009). Análisis del concepto de Responsabilidad Social Empresarial. International Journal of Good Conscience, 9 [en línea]. Disponible en: http://www.comunicarseweb.com.ar/varias/ que-es-comunicarse.html (Consultado sep. 22-14).

13. CÓRDOB, Juan \& VICENTELLI, Amanda (2009). Gobierno Corporativo. Colombia Capital, un punto de encuentro para inversionistas, 15 [en línea]. Disponible en: https://www.governanceconsultants. com/wp-content/uploads/2015/04/2009_Cartilla-BVC-GOBIERNO-CORPORATIVO.pdf (Consultado jul. 9-14).

14. CORREA, Guillermo (2007). Evolución histórica de los conceptos de responsabilidad social empresarial y balance social. Semestre Económico - Universidad de Medellin. Vol. 10, Núm. 20, pp. 87-102 [en línea]. Disponible en: https http://www.scielo.org.co/scielo.php?pid=S012063462007000200006\&script=sci_arttext\# (Consultado jul. 9-14).

15. CRESPO, Faride (2010). Entre el concepto y la práctica: responsabilidad social empresarial. Estudios Gerenciales, Vol. 26, Núm. 117, pp. 119-130 [en línea]. Disponible en:<http://www.redalyc.org/articulo. oa?id=21218551006> (Consultado sep. 22-14).

16. DAVIDSON, Paul y GRIFFIN, Ricky (2000). Management: Australia in a global context. Wiley, Brisbane. De George, R. T. 1999. Business Ethics, 5th Edition. Prentice Hall, Upper Saddle River, NJ.

17. DERES (2010). Análisis del concepto de Responsabilidad Social Empresarial. International Journal of Good Conscience, 13 [en línea]. Disponible en:<http://www.redalyc.org/articulo. oa?id=21218551006> (Consultado sep. 22-14).

18. DET NORSKE VERITAS (2010). "Integración del Modelo EFR con otros modelos de Gestión dentro de la organización. RSC Vs. EFR", pp. 12-13.

19. DÍAZ, Danel (2010). Mejores Practicas de Gobierno Corporativo. 7ª. Convención Nacional de la Red de la Gente, México: Control de Gestión de Negocios, S.C.

20. DOBELE, A., WESTBERG, K., STEEL, M., FLOWERS, K. (2014). An Examination of Corporate Social Responsibility Implementation and Stakeholder Engagement: A Case Study in the Australian Mining Industry, Business Strategy and the Environment, Vol. 23. Núm. 3, pp. 145-159.

21. DRUCKER, Peter (2003). Managing For The Future. The 1990's and Beyond, 8. 
José Javier González Millán, Miryam Teresa Rodríguez Díaz, Jenny Mairena Herrera Rodríguez Prácticas de responsabilidad social y gobierno corporativo. Un análisis para el sector bancario de Sugamuxi

22. DURANGO, Carlos (2005). Fundamentación Epistemológica de los estudios organizacionales. Medellín, Colombia: Universidad Pontificia Bolivariana.

23. FERNÁNDEZ, Guadaño (2012). Desempeño de las empresas propiedad de sus trabajadores: ¿Un modelo de gobierno corporativo laboral?. INNOVAR. Revista de Ciencias Administrativas y Sociales, Vol. 22, Núm. 43, pp. 33-43 [en línea]. Disponible en: http://www.revistas.unal.edu.co/index.php/ innovar/article/viewFile/35507/35885 (Consultado sep. 22-14).

24. FERREIRA, Roberto; SANTOS, Antônio; LOPES, Ana; \& Fonseca, Reinaldo (2013). Governança corporativa, Eficiência, Produtividade e Desempenho. RAM. Revista de Administração Mackenzie, vol.14, n.4, pp. 134-164 [en línea]. Disponible en: $<$ http://www.scielo.br/scielo.php?script=sci_arttext\&pid=S167869712013000400006\&lng=pt\&nrm=iso (Consultado sep. 22-14).

25. FORÉTICA (2008). Análisis del concepto de Responsabilidad Social Empresarial. International Journal of Good Conscience, 9.

26. FRIEDMAN, Milton (2000). The Social Responsibility of Business is to Increase its Profits, in Des Jardins, J. R. and J. Mc Cal. led. Contemporary Issues in Business Ethics. Wadsworth, Belmont, CA, pp. 8-12.

27. FUNDARSE (2007). Análisis del concepto de Responsabilidad Social Empresarial. International Journal of Good Conscience, 12 [en línea]. Disponible en: http://www.fundahrse.org (Consultado sep. 22-14).

28. GALLEGO, Álvarez; GARCÍA, Sánchez y RODRÍGUEZ, Domínguez (2009). La eficacia del gobierno corporativo y la divulgación de información en internet. Investigaciones Europeas de Dirección y Economía de la Empresa, Vol. 15, Núm.1. pp 109-135 [en línea]. Disponible en: http://www.redalyc. org/articulo.oa?id=274120370007 (Consultado ago. 15-14).

29. GANGA, Francisco y VERA, José (2008). El gobierno corporativo: consideraciones y cimientos teóricos. Cuadernos de Administración, Vol. 21, Núm. 35. pp. 93-126 [en línea]. Disponible en: http://www. redalyc.org/articulo.oa?id=20503505 (Consultado sep. 22-14).

30. GARCÍA, Heriberto; CORTEZ, Aimer y RODRÍGUEZ, Martha (2009). Activismo legal como factor de cambio en el gobierno corporativo. Cuadernos de administración, Vol. 22, Núm. 8, pp. 31-47 [en línea] Disponible en:<http://www.redalyc.org/articulo.oa?id=20511730003 (Consultado dic. 06-14).

31. GONZÁLEZ, Patricia (2002). El gobierno corporativo en el Brasil y el papel social de las empresas. Estudios Gerenciales, Vol. 83, pp. 71-89 [en línea] Disponible en: http://www.redalyc.org/articulo. oa?id=21208304 > ISSN 0123-5923 (Consultado dic. 09-14).

LAMEIRA, De Jesus; LEE NESS, Walter; y VAN ADUARD, Diana (2007). Governança corporativa: impactos no valor das companhias abertas brasileiras. Revista de Administração - RAUSP, Vol. 42, Núm. 1, pp. 64-73. [en línea] Disponible en: http://www.redalyc.org/articulo.oa?id=223417433006 (Consultado dic. 07-14).

32. LEFORT, Fernando (2003). Gobierno corporativo: ¿que es? y ¿como andamos por casa?. Cuadernos de economía. Vol. 40, Núm. 120, pp. 207-237 [en línea] Disponible en: http://www.scielo.cl/ scielo.php?script=sci_arttext\&pid=S0717-68212003012000002\&lng=es\&tlng=es. 10.4067/S071768212003012000002 (Consultado mar. 04-2014).

33. LIBRO VERDE, C. E. (2001). Análisis del concepto de Responsabilidad Social Empresarial. International Journal of Good Conscience, 8.

34. LONGINOS, Joaquin; ARCAS, Narciso; MARTÍNEZ, Inocencia; y OLMEDO, Isabel (2012). Transparencia, gobierno corporativo y participación: claves para la implantación de un código de conducta en empresas de economía social. revesco. Revista de Estudios Cooperativos, Vol. 108, pp. 86-112 [en línea] 
Disponible en:<http://www.redalyc.org/articulo.oa?id=36723199004> ISSN 1135-6618 (Consultado mar. 04-2014).

35. MÉNDEZ, Carlos (1998). Metodología, Guía para Elaborar Diseños de Investigación en Ciencias Económicas, Administrativas y contables, Fundamentos Teóricos. Bogotá D.C., Colombia: Mc Graw Hill.

36. MAROTO, Juan; MELLE, Mónica; MORENO, Ignacio y RODRÍGUEZ, José (2006). Grado de competencia, presión de la deuda y productividad empresarial: un análisis empírico desde la perspectiva del gobierno corporativo. Panorama Socioeconómico, Vol. 24. Núm. 33, pp. 8-17 [en línea] Disponible en: http://www.redalyc.org/articulo.oa?id=39903302 (Consultado nov. 8-2014).

37. MCWILLIAMS Abagail; SIEGEL, Donald. Y WRIGHT, Patric (2006). Corporate Social Responsibility: Strategic Implications. Journal of Management Studies Vol.43. Núm. 1, pp 1-18 [en línea] Disponible en: http://citeseerx.ist.psu.edu/viewdoc/download?doi=10.1.1.460.8252\&rep=rep1\&type=pdf (Consultado nov. 8-2014).

38. MELLADO, Claudia (2009). Responsabilidad Social Empresarial en las Pequeñas y Medianas Empresas latinoamericanas. Revista de Ciencias Sociales. Vol. XV, pp. 24-33 [en línea] (Disponible en: $<$ http:// www.redalyc.org/articulo.oa?id=28011674003 (Consultado dic. 4-2014).

39. OIT (2007). Análisis del concepto de Responsabilidad Social Empresarial. International Journal of Good Conscience, 7.

40. PARDO, Orlando (2003). Democracia y gobierno en la universidad. Reflexión Política, Vol. 5. Núm. 10, pp. 128-135. 33 [en línea] Disponible en: http://www.redalyc.org/articulo.oa?id=11051011 (Consultado nov. 8-2014).

41. PEÑA, David; Y SERRA, Antoni (2012). Responsabilidad Social Empresarial En El Sector Turístico. Estudio de caso en empresa de alojamiento de la ciudad de Santa Marta, Colombia. Estudios y Perspectivas en Turismo, Vol. 21. Núm. 6, pp. 1456-1480. 33 [en línea] Disponible en: http://www.redalyc.org/ articulo.oa?id=180725030006 (Consultado jun. 13-2014).

42. PINEDA, Alonso y TORRES DE MARÍN, Gabriela (2005). Gobierno corporativo. Juntas Directivas. Una perspectiva global, nacional y regional. Revista Ciencias Estratégicas, vol. 13, núm. 14, julio-diciembre, 2005, pp. 177-194 [en línea] Disponible en: http://redalyc.org/articulo.oa?id=151321068005 (Consultado nov. 8-2014).

43. RODRÍGUEZ, María. (2005). La Responsabilidad Social Empresarial y los consumidores. CIRIEC-España, Revista de Economía Pública, Social y Cooperativa, núm. 53, noviembre, 2005, pp. 97-109 [en línea] Disponible en: http://redalyc.org/articulo.oa?id=17405308 (Consultado abr. 25-2014).

44. SCHERMERHORN, John (2002). Análisis del concepto de Responsabilidad Social Empresarial. International Journal of Good Conscience, 3. 7th edition. Wiley, New York.

45. SOLÍS, José (2008). Responsabilidad social empresarial: un enfoque alternativo. Análisis Económico, vol. XXIII, núm. 53, 2008, pp. 227-252 [en línea] Disponible en: http://www.redalyc.org/articulo. oa?id=41311449011 (Consultado jul. 9-14).

46. TAMAYO, Mario (2002). El Proceso de la Investigación Científica, La Investigación Científica. Balderas, México: Limusa Noriega Editores.

47. VERGARA, María Pula y VICARÍA, Laura (2009). "Ser o aparentar la responsabilidad social empresarial en Colombia". Análisis organizacional basado en los lineamientos de la responsabilidad Social Empresarial. Trabajo de Grado para optar por el título de Comunicador Social con énfasis en Comunicación Organizacional. Bogotá, Colombia. 